\title{
Synergistic Disease in Pepper Caused by the Mixed Infection of Cucumber mosaic virus and Pepper mottle virus
}

\author{
John F. Murphy and Kira L. Bowen
}

Department of Entomology and Plant Pathology, 209 Life Sciences Building, Auburn University, AL 36849.

Accepted for publication 11 November 2005.

\begin{abstract}
Murphy, J. F., and Bowen, K. L. 2006. Synergistic disease in pepper caused by the mixed infection of Cucumber mosaic virus and Pepper mottle virus. Phytopathology 96:240-247.

The occurrence of more than one virus species in a single plant is not uncommon in cultivated and native plant species. A mixed virus infection may lead to greater disease severity than individual viral components and this is sometimes referred to as a synergistic disease. Although, in some cases, synergism has been demonstrated for various plant growth parameters such as plant height, weight, and yield, proof of synergy typically has not been demonstrated for symptom severity when the mixed virus infection was not lethal. We demonstrated synergy in bell pepper plants co-infected with Cucumber mosaic virus (CMV) and Pepper mottle virus

and aboveground fresh weight (one of three trials) using factorial analysis and Abbott's equation for synergy. This approach allowed affirmation of the type of response (i.e., synergistic rather than antagonistic) and statistical proof of synergy. A detailed evaluation of symptom severity for each viral treatment revealed three phases associated with host plant developmental stages. A numerical symptom severity rating scale was developed and used in each of two equations to demonstrate statistical proof for synergy based on symptom severity for co-infected plants. Virus accumulation in noninoculated leaves was determined by enzyme-linked immunosorbent assay. In singly infected plants, CMV titers declined in mildly symptomatic leaves representing later stages of plant development, but titers increased in similar leaves of co-infected plants. In contrast, PepMoV titers did not differ in singly or co-infected plants.
\end{abstract} (PepMoV) relative to each virus alone for stem height (two of three trials)
It is not uncommon for two or more plant virus species to infect a single plant in nature. We detected numerous combinations of mixed virus infections when surveying commercial vegetable and wheat crops in Alabama $(4,21,22,31)$. Although some mixed virus infections resulted in an unusually severe disease, other mixed infections had disease symptoms of one virus which appeared to mask the symptoms typically induced by the others. When mixed virus infection does lead to severe disease symptoms, however, it sometimes is referred to as being synergistic.

A few of the more well-defined viral synergistic diseases occur in corn (referred to as corn lethal necrosis) (23), cowpea (referred to as cowpea stunt) (24), soybean $(6,27)$, and tobacco (8). In each of these cases, the classification of synergism initially was associated with extreme disease severity resulting from mixed virus infection. A mixed virus infection in corn consisting of Maize chlorotic mottle virus and either Wheat streak mosaic virus or Maize dwarf mosaic virus resulted in plant death, whereas plants infected with each virus alone expressed what might be considered typical systemic virus symptoms, such as varying degrees of mosaic $(23,30)$. A similar response was reported for zucchini squash plants infected with Cucumber mosaic virus (CMV) and Zucchini yellow mosaic virus $(7,34)$. Plant death resulting from mixed virus infection is unquestionably a synergistic interaction. Sweet potato plants co-infected with Sweet potato feathery mottle virus and Sweet potato chlorotic stunt virus developed severe disease symptoms which, in most circumstances, may not have been considered a synergistic disease; however, indi-

Corresponding author: J. F. Murphy; E-mail address: murphjf@ auburn.edu

* The $\boldsymbol{e}$-Xtra logo stands for "electronic extra" and indicates that the online version contains supplemental material not included in the print edition. Figure 1 appears in color online.

DOI: 10.1094/PHYTO-96-0240

(C) 2006 The American Phytopathological Society vidual infections were symptomless or caused only very mild symptoms (17).

Synergism resulting from mixed virus infection also has been determined using growth parameters such as plant height, weight, yield, and effects on seed $(3,6,19,24,27,35)$. In a few cases, synergism was recognized as an increase in accumulation of one or both viruses in the mixed infection relative to each virus alone $(16,25,29,35)$. This occurrence, that virus accumulation differs for one or both viruses when in a mixed infection relative to singly infected plants, appears to be a common result of mixed virus infections. It also appears to be common for one of the viral components in a mixed infection that leads to synergistic disease to be in the genus Potyvirus $(6-8,10,12,17,23-25,27,28,35)$.

In some cases, synergy associated with disease severity for mixed virus infection has been based more on qualitative than quantitative approaches (i.e., identification of synergy has been associated with increased disease severity without statistical proof of synergy). Significant reductions in growth characteristics (i.e., quantitative parameters) such as height, weight, and yield have been shown in response to mixed infection; however, evaluations for symptom severity have remained primarily descriptive, without a statistical basis for the occurrence of synergy. A quantitative approach has been used to determine synergy for the interaction between two fungicides for disease control. With fungicide combinations, a synergistic interaction was indicated when the observed percent disease control was greater than the expected disease control (18) and statistical proof that synergy exists when a significant interaction occurs between the two factors (i.e., fungicides) in the experiment (32). Stated another way, when there is a significant interaction, the response may be synergistic or antagonistic; synergy is distinguished from antagonism by the relationship of the observed to the expected response (i.e., whether the observed response is greater than or less than the expected response). If percent reductions in plant growth response due to infection by a virus are used instead of percent disease control by 
a fungicide, the occurrence of synergy due to virus interactions can be predicted in a manner similar to that presented by Kosman and Cohen (18).

Capsicum annuum 'Early Calwonder' (pepper) plants have been used as a susceptible control for CMV (genus Cucumovirus) and Pepper mottle virus (PepMoV; genus Potyvirus) in previous studies $(2,13,15,20)$. During several projects, we noted extremely severe but nonlethal symptoms in pepper plants co-infected with CMV and PepMoV relative to infection with either virus alone in experiments carried out under greenhouse conditions. It was unclear to us, however, how to prove synergy for symptom severity of a systemic virus disease when each virus alone induced systemic symptoms and the co-infected plants were more severely affected but without a lethal response. In this report, we evaluated commonly used quantitative measures of disease, plant height, and aboveground fresh weight to provide proof of synergy using statistical analyses and Abbott's equation for synergy. Of particular interest to this project was the ability to test for synergy based on symptom severity. To address this issue, two equations were developed to allow statistical proof of synergy for the qualitative trait of symptom severity. The virus titer for single and mixed infections also was analyzed in an effort to explain the increase in symptom severity due to mixed infection of CMV and PepMoV in Early Calwonder plants.

\section{MATERIALS AND METHODS}

Plant growth conditions. C. annuum cv. Early Calwonder was used for all experiments. Early Calwonder seed was sown in Styrofoam trays (72 wells per tray) containing Pro-Mix soilless potting medium (Premier Peat, Riviére-du-Loup, Québec, Canada). Upon germination, seedlings were transplanted to 2-liter pots (one plant per pot) containing Pro-Mix. Experiments were performed in a temperature-controlled greenhouse at the Plant Science Greenhouse Complex at Auburn University, AL. Ambient air temperatures in the greenhouse were maintained at 28 and $21^{\circ} \mathrm{C}$ during the day and night, respectively, throughout the year. Watering procedures were those carried out routinely by greenhouse personnel.

Virus isolates and inoculation procedures. CMV subgroup I strain Fny was provided by P. A. Palukaitis (Scottish Crop Research Institute, Invergowrie, Scotland). PepMoV strain Florida originally was obtained by T. A. Zitter (Cornell University). Each virus was maintained (separately) in the greenhouse by mechanical passage (i.e., rub inoculation) in Nicotiana tabacum cv. Kentucky 14 and Early Calwonder. CMV and PepMoV inocula consisted of systemically infected Kentucky 14 leaf tissue ground in $50 \mathrm{mM}$ potassium phosphate buffer, $\mathrm{pH} 7.0$, containing $10 \mathrm{mM}$ sodium sulfite at a ratio of $1 \mathrm{~g}$ of tissue to $10 \mathrm{ml}$ of buffer. The combined inoculum of CMV and PepMoV (hereafter referred to as $\mathrm{CMV}+\mathrm{PepMoV}$ ) consisted of similar amounts of tissue as used for inoculum consisting of each virus alone, ground together in the appropriate amount of buffer. The CMV+PepMoV inoculum consisted of two preparations of infected tissue and corresponding amount of buffer; therefore, healthy tobacco tissue and the appropriate amount of buffer was added to each single inoculum (CMV or PepMoV alone) in an effort to equalize amounts of tissue and buffer among inocula. A mock-inoculated treatment was included that consisted of healthy tobacco tissue ground in the appropriate amount of buffer. Buffer, mortars, and pestles were chilled prior to use and maintained on ice during inoculations. Leaves to be inoculated were lightly dusted with Carborundum prior to inoculation.

Treatments (CMV alone, PepMoV alone, CMV+PepMoV, and mock) were arranged in a randomized complete block design with five plants of each treatment per replication (i.e., a row of five plants) and four replications per treatment. Four experiments were performed; in each case, the 20 pepper plants per treatment were mechanically (rub) inoculated onto leaves one through three (the three oldest leaves) with virus or mock when plants were at the seven- to eight-leaf stage. The description for phyllotaxic development of pepper leaves along the stem was reported by Andrianifahanana et al. (2). Briefly, leaves emerge in pairs on opposite sides of the stem, typically at a single node for the first few pairs of leaves but separated with increasing lengths of internode between subsequently emerging leaf pairs. The main stem branches into two stems at approximately leaf 10, with leaves 11 and 12 each typically occurring on separate stems. Leaf emergence as pairs of leaves then occurs along each secondary stem.

Evaluation of plant growth characteristics as disease assessments. Plant growth characteristics evaluated for each viral and mock treatment included plant height and total fresh weight of aboveground tissues. Plant height was determined as a measure of stem length in centimeters from soil level to stem tip. This measurement was taken 1 day prior to inoculation and at 21 or 25 days postinoculation (dpi) and is presented as the difference between the two measurements. Plant fresh weight of aboveground tissues was determined by cutting the stem at the soil line and immediately weighing all associated tissues (e.g., stem, leaves, and flowers) at 21 or 25 dpi. Experiments were performed in April, September, and October 2003. Percent reduction in plant growth and weight, based on the growth and weight numbers, respectively, of control plants in each replication, was calculated for each plant of each replication. Percent reduction data were subjected to analysis of variance (ANOVA) and means differentiated with Fisher's protected least significant difference with $P=0.05$. Means were used to calculate the expected response $\left(\mathrm{C}_{\text {exp }}\right)$ from the co-infection of two viruses using equation 1 (14). The $C_{\exp }$ was compared with the observed response $\left(\mathrm{C}_{\mathrm{obs}}\right)$ and when $\mathrm{C}_{\mathrm{obs}}>$ $\mathrm{C}_{\text {exp }}$, a synergistic interaction was indicated:

$$
\mathrm{C}_{\mathrm{exp}}=\mathrm{A}+\mathrm{B}-(\mathrm{AB} / 100)
$$

where $\mathrm{C}_{\exp }$ is the expected level of disease, and $\mathrm{A}$ and $\mathrm{B}$ are proportional responses due to infection by virus $\mathrm{A}$ and $\mathrm{B}$, respectively, as measured.

Factorial analysis then was used to test the significance of the interaction. The two main effects were each of the viruses, CMV or PepMoV, and each main effect had two levels, true inoculation or mock inoculation. When the interaction term of this factorial is statistically significant, the two viruses are not acting independently of one another (32). Stated differently, significance of this interaction term indicates that one factor (i.e., presence of CMV) has an influence on the effects due to the other factor (in this case, PepMoV), and this effect is greater than mere additivity or the sum of the two factors together.

Evaluation of symptom severity as a measure of synergy. The timing of appearance and severity of virus-induced symptoms were evaluated throughout the course of each of three experiments that included plant growth parameter measurements as described above. Symptom rating scales evolved with each experiment and, in each case, attempts were made to simplify the rating system. Detailed evaluations revealed three distinct phases in symptom development that were used to generate a symptom severity-based rating scale (Table 1). Symptom descriptions and ratings are presented in Results with accompanying data from an experiment performed in April 2005. A mean value for symptom severity ratings among virus treatments for each symptom phase was used to test for synergy using the following equations:

$$
\mathrm{S}_{\mathrm{obs}}=(\mathrm{W}+\mathrm{X}+\mathrm{Y})
$$

where $\mathrm{W}=$ mean disease rating for symptom phase $1, \mathrm{X}=$ mean disease rating for symptom phase 2 , and $\mathrm{Y}=$ mean disease rating for symptom phase 3 ; and

$$
\mathrm{S}_{\mathrm{obs}}=(\mathrm{W}+\mathrm{X}+\mathrm{Y}+\mathrm{Z})
$$

where $\mathrm{Z}=$ whole-plant disease phenotype evaluation for the disease caused by each viral treatment and was determined at the end 
of the experiment. In this case, the rating for $\mathrm{Z}$ was either -1 , symptom development showed a remission in severity; 0 , symptom severity remained similar or constant throughout the experiment; or +1 , symptoms continued to progress in severity with a continuation in plant decline.

It is important to note that each symptom phase represented a progressive, new stage of plant development and the associated disease manifested in that stage. Thus, each symptom phase was correlated with a distinct host developmental stage. Symptom ratings taken at a particular phase did not reflect symptom ratings for tissues from the previous phase which may have remained the same, become milder or increased in severity. The $\mathrm{Z}$ parameter was used to evaluate the whole-plant disease phenotype at the completion of the experiment.

Virus accumulation in noninoculated leaves. The relative amount of virus accumulation in systemically infected leaves was determined by antigen plate-coating, indirect enzyme-linked immunosorbent assay (ELISA) as described by Garcia-Ruiz and Murphy (13). A sample, consisting of two noninoculated leaves, was collected from each plant at 10 and 21 dpi (trials 2 and 3) and tested by ELISA. Samples were considered positive for the presence of CMV or PepMoV when the absorbance value (at $405 \mathrm{~nm}$ ) was greater than the mean plus three standard deviations for comparable healthy control samples.

\section{RESULTS}

Synergism based on plant height and fresh weight. Plants in each treatment were compared for stem height (the difference in stem height 1 day prior to inoculation and at the end of the experiment) and aboveground fresh weight at 21 or 25 dpi. In each of three trials, growth in stem height and final aboveground fresh weight of plants that were co-infected with $\mathrm{CMV}+\mathrm{PepMoV}$ were significantly less than that of plants inoculated with either virus alone $(P<0.05)$ (Table $2 \mathrm{~A})$. In addition, plants infected with either virus alone or co-infected with $\mathrm{CMV}+\mathrm{PepMoV}$ resulted in less stem height and aboveground fresh weight than observed in mock-inoculated controls (Table 2A). Based on equation 1, the observed responses to co-infection with $\mathrm{CMV}+\mathrm{PepMoV}$ are greater than expected, and this suggests a synergistic effect on both measured variables in each trial (Table 2B). However, this is only an indication of the type of response (i.e., $\mathrm{C}_{\mathrm{obs}}>\mathrm{C}_{\mathrm{exp}}$ indicates synergy versus $\mathrm{C}_{\mathrm{obs}}<\mathrm{C}_{\mathrm{exp}}$ for antagonism) and is not statistical proof of that response.

TABLE 1. Symptom description and severity rating for pepper plants infected with Cucumber mosaic virus (CMV), Pepper mottle virus (PepMoV), and the combined infection of $\mathrm{CMV}+\mathrm{PepMoV}$

\begin{tabular}{ll}
\hline Symptom phase, rating & \multicolumn{1}{c}{ Symptom description } \\
\hline Phase 1 & Vein clearing, chlorosis, mild mosaic \\
+1 & Mosaic or mottle \\
+2 & Mosaic and mottle \\
+3 & Mosaic, mottle, change in leaf texture (dullness) \\
Phase 2 & Mosaic, mottle, reduced leaf size with deformation \\
+1 & Severe mosaic, mottle, leaf stunting, deformation \\
+2 & Mild, if any, mosaic, reduced leaf size without deformation \\
+3 & Mosaic, mottle, reduced leaf size with deformation \\
Phase 3 & Severe mosaic, leaf stunting, deformation, halted stem extension \\
+1 & \\
+2 & Remission of symptoms (i.e., reduced severity) \\
+3 & No change in symptoms for new leaves relative to phase 2 \\
Whole-plant disease phenotype & Dramatic increase in symptom severity, continued plant decline \\
-1 & \\
0 & \\
+1 & Each symptom phase represented a progressive, new stage of plant development and the associated disease manifested during that stage. Thus, each symptom \\
phase was correlated with a distinct host developmental stage. Symptom ratings taken at a particular phase did not reflect symptom ratings for tissues from the \\
previous phase which may have remained the same, become milder or increased in severity. The whole plant disease phenotype parameter was taken at the \\
completion of the experiment.
\end{tabular}

TABLE 2. Growth and aboveground fresh weight of pepper plants not subjected to virus inoculation (control) or inoculated with Cucumber mosaic virus (CMV), Pepper mottle virus (PepMoV), or a combined inoculum of CMV+PepMoVw

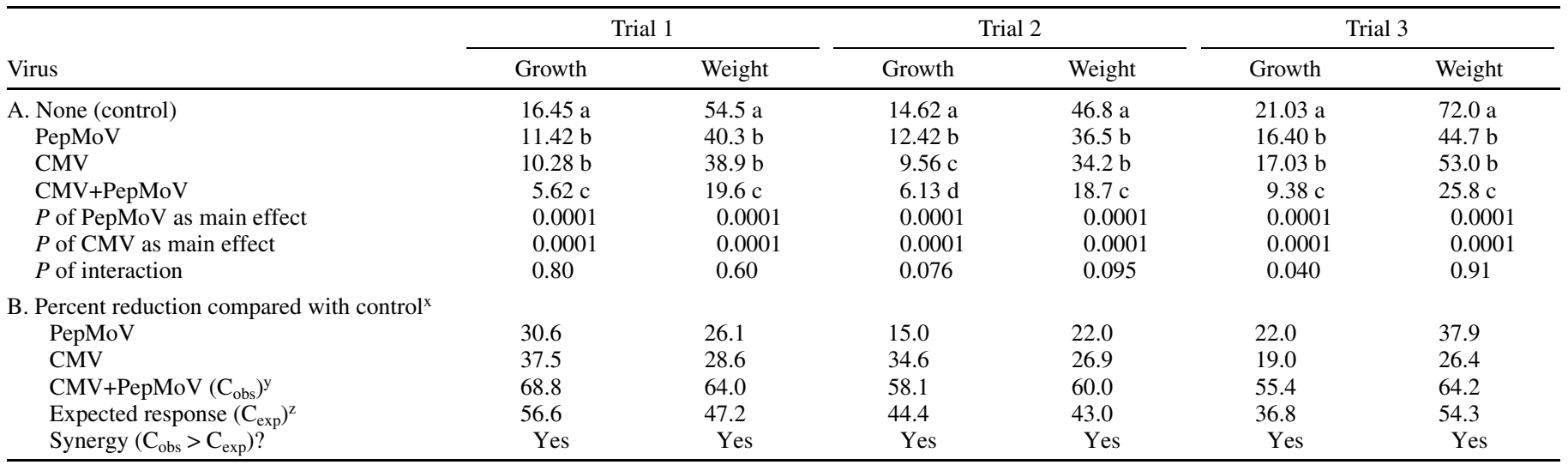

${ }^{w}$ Growth is the difference in height from one day prior to virus inoculation to 21 or 25 days postinoculation. Letters following means in columns, when different, indicate a significant difference according to Fisher's least significant difference at $P=0.05$.

${ }^{x}$ Percent reduction compared with control; percent reduction in growth or aboveground fresh weight based on growth and weight of control plants.

${ }^{y} C_{\text {obs }}=$ observed response.

${ }^{\mathrm{z}} \mathrm{C}_{\mathrm{exp}}=\mathrm{A}+\mathrm{B}-(\mathrm{AB} / 100)$, where A represents PepMoV and B represents CMV. 
Factorial analysis of data from each trial revealed that the interaction between CMV and PepMoV had a significant $(P<0.10)$ effect on stem height in trials 2 and 3 and on aboveground fresh weight in trial 2 (Table 2A). The significant interaction shows that the two viruses are not acting independently. However, significance of the interaction term alone does not demonstrate synergy because the interaction could be antagonistic. Demonstration of a synergistic response requires both affirmation of the type of the response (e.g., through equation 1) and statistical proof that the factors are not independent of one another (32). Thus, in two of the three trials, a synergistic effect due to co-infection was both observed and demonstrated to be statistically significant on stem height. There was not as consistent proof of a synergistic effect on plant weight. These results with plant weight may not be unexpected given that internode extension was dramatically negatively affected for $\mathrm{CMV}+\mathrm{PepMoV}$-infected plants, but with con- tinued production of foliar tissues despite leaf and stem dwarfing. Furthermore, the dramatic increase in symptom severity for CMV+ PepMoV-infected plants relative to plants infected with each virus alone occurred at later stages in the experiment with comparatively similar stem and leaf development through earlier stages of disease development (described in detail below).

Synergism based on symptom severity. The combined infection of $\mathrm{CMV}+\mathrm{PepMoV}$ resulted in a synergistic interaction manifested as reductions in stem height in two trials and aboveground fresh weight of Early Calwonder plants in one trial relative to infection by either virus alone. Although these parameters are representative of disease responses by the host plants, our primary interest was to attempt determination of a synergistic interaction based on symptom severity. Phenotypic evaluations suggested that co-infection with CMV+PepMoV led to a synergistic interaction (Fig. 1). In an effort to determine whether this synergy was meas-
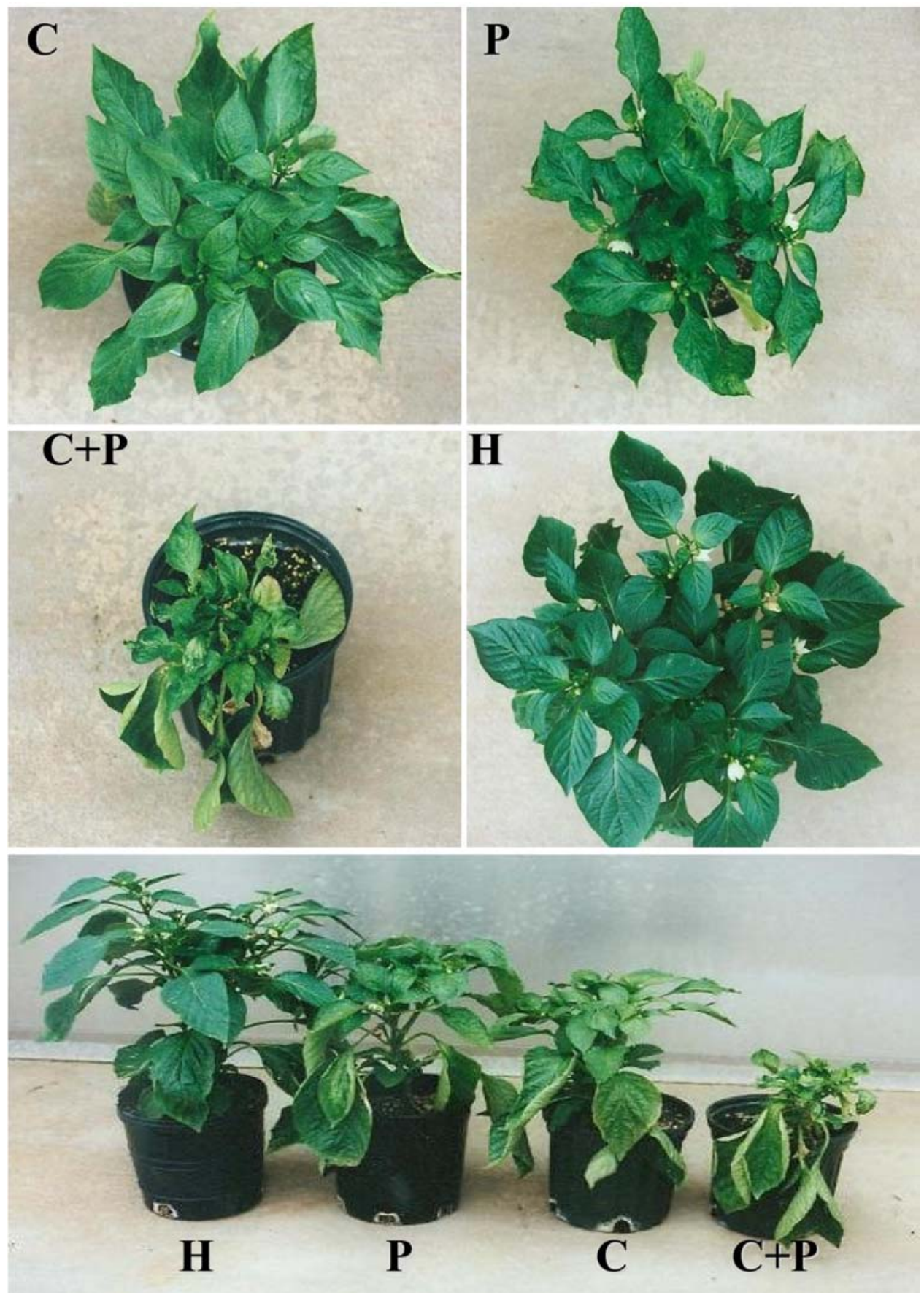

Fig. 1. Symptoms induced by Cucumber mosaic virus $(\mathrm{C})$, Pepper mottle virus $(\mathrm{P})$, and the combined infection of $\mathrm{C}+\mathrm{P}$ at 21 days postinoculation. A comparable mock-inoculated plant is included $(\mathrm{H})$. 
urable through host symptomatic response, disease severity rating scales were developed for each of the viral treatments. As with most systemic plant virus infections, however, symptom development for each viral treatment was progressive as the virus moved into and infected newly emerged tissues. In our case, and perhaps with other virus-host systems, this progression in disease generally is expected to increase over time. For example, as new leaves emerged and were symptomatic, the area under the disease progress curve was expected to increase. Thus, new phases of disease that occurred in newly emerged leaves tended to be identified with incremental increases in disease severity rating. A more detailed evaluation, however, led us to realize that, although new "phases" of the disease may develop, they may not necessarily be more severe and, in some cases, previous phases of disease may fade or even disappear with time.

Symptom development for each of the virus treatments in Early Calwonder plants occurred in three phases, with each new phase occurring successively in time, referred to hereafter as phases 1 , 2 , and 3 . A disease rating scale was generated for each symptom phase, with the rating then used in equations $2 \mathrm{a}$ and $2 \mathrm{~b}$ to determine synergy (Table 3 ). Consistency in experimental design in the controlled conditions of the greenhouse resulted in uniformity of disease development within virus treatments from one experiment to another. Thus, symptom development was extremely consistent for each virus treatment throughout the course of this project. Although the symptom rating may have varied for a particular virus when determined at a given time point post inoculation (as illustrated in Table 3), in time, each virus treatment was consistent in the progression of its particular disease-related symptoms.

Disease severity for each of the virus treatments was relatively similar through phase 1 . This phase represented systemic symptoms that occurred on plants that were at the stage of development prior to branching (up to approximately the 9- to 10-leaf stage). Through phase 1, CMV-induced symptoms consisted of chlorosis at the base of young leaves by 5 to $7 \mathrm{dpi}$ that progressed into a chlorotic mosaic that covered from the basal half to the entire portion of young leaves. The next two to three leaves that emerged had mosaic symptoms over the entire leaf blade. CMV symptom ratings averaged 2.0 for phase 1 . Phase 1 symptoms for PepMoV appeared between 5 to $7 \mathrm{dpi}$ in the form of vein clearing. Leaves four and five were immediately above the inoculated leaves and either did not develop symptoms or developed vein clearing over the basal half of the leaf. Younger leaves developed vein clearing that progressed into a mottle or were mottled without any apparent vein clearing. PepMoV symptom ratings averaged 2.0 for phase 1 . Through phase 1 for CMV+PepMoV-infected Early Calwonder plants, systemic symptoms appeared between 5 to 7 dpi and included chlorosis along the basal portion of young leaves and vein clearing, which were representative of each of the viruses. Systemic symptoms progressed into more extensive chlorosis with both mosaic and mottle as the plants approached the 9- to 10-leaf stage. Plant growth and symptom severity for plants infected with $\mathrm{CMV}+\mathrm{PepMoV}$ were relatively similar to those observed in plants infected with each virus alone during the early portion of phase 1, with greater disease severity resulting in co-infected plants during later portions of phase 1 . CMV+PepMoV symptom ratings averaged 3.0 for phase 1 .

Phase 2 represented the pepper plant growth phase at and shortly after branching of the stem with branching occurring at approximately the 10-leaf stage. During phase 2 (generally leaves 10 through 14), CMV-infected plants were moderately stunted compared with mock-inoculated control plants. Older leaves that expressed symptoms during phase 1 were, at this time, only mildly symptomatic, with newly emerged leaves in phase 2 having less obvious chlorosis and mosaic symptoms due to CMV infection. Instead, CMV-infected leaves at and just above the point of the stem branch had a dull green color and varying degrees of deformation. Overall, CMV-infected plants appeared less severely symptomatic than during phase 1. CMV symptom ratings averaged 1.2 for phase 2. Through phase 2 for PepMoV-infected plants, there was some overall stunting relative to mock-inoculated controls and all newly emerged leaves had an obvious mottle symptom and were smaller in size than comparable leaves of control plants. Leaves that expressed mottle in phase 1 retained their mottled appearance during phase 2. PepMoV symptom ratings averaged 1.9 for phase 2. CMV+PepMoV-infected plants entering phase 2 expressed a dramatic increase in disease severity. Elongation of the stem appeared to stop at or just above the point of stem branching, expanded leaves were deformed and severely downward cupped, and emerging leaves remained very small and deformed. $\mathrm{CMV}+\mathrm{PepMoV}$ symptom ratings averaged 3.0 for phase 2 . It was during phase 2 that the three virus treatments began to diverge in symptom severity, with CMV-infected plants appearing less symptomatic, PepMoV-infected plants essentially remaining at a similar level of symptom severity, and CMV+PepMoV-infected plants showing a dramatic increase in symptom severity relative to phase 1 .

Phase 3 symptom rating was performed after secondary stem elongation for CMV- and PepMoV-infected plants (and mockinoculated plants); approximately from leaf 14 and beyond. CMVinfected plants appeared to have recovered from infection during phase 3 with some overall stunting; emerging and recently expanded leaves continued to be a mildly dull green color but with less deformation, if any, compared with symptoms observed with phase 2 (Fig. 1, C). Newly emerged CMV-infected leaves tended to be smaller than comparable leaves of control plants. CMV symptoms from phase 1 were no longer apparent, but those from

TABLE 3. Means of symptom ratings for 20 plants for each inoculative treatment for each of three phases of disease development ${ }^{\mathrm{V}}$

\begin{tabular}{|c|c|c|c|c|c|c|}
\hline \multirow[b]{2}{*}{ Virus $^{\mathrm{w}}$} & \multicolumn{4}{|c|}{ Rating (actual) ${ }^{\mathrm{x}}$} & \multirow[b]{2}{*}{ Whole-plant ${ }^{\mathrm{y}}$} & \multirow[b]{2}{*}{ Phase sum, whole (eq. $2 b)^{z}$} \\
\hline & Phase 1 & Phase 2 & Phase 3 & Phase sum (eq. 2a) & & \\
\hline CMV & 2.0 & 1.2 & 1.1 & $4.3 \mathrm{~b}$ & -0.9 & $3.4 \mathrm{~b}$ \\
\hline PepMoV & 2.0 & 1.9 & 2.1 & $6.0 \mathrm{c}$ & -0.2 & $5.8 \mathrm{c}$ \\
\hline CMV+PepMoV & 3.0 & 3.0 & 3.0 & $9.0 \mathrm{~d}$ & 1.0 & $10.0 \mathrm{~d}$ \\
\hline Mock & 0.0 & 0.0 & 0.0 & $0.0 \mathrm{a}$ & 0.0 & $0.0 \mathrm{a}$ \\
\hline$P$ of $\mathrm{CMV}$ as main effect & $\ldots$ & $\ldots$ & $\ldots$ & $<0.0001$ & $\ldots$ & $<0.0001$ \\
\hline$P$ of PepMoV as main effect & $\ldots$ & $\ldots$ & $\ldots$ & $<0.0001$ & $\ldots$ & $<0.0001$ \\
\hline$P$ of interaction & $\ldots$ & $\ldots$ & $\ldots$ & 0.0002 & $\ldots$ & $<0.0001$ \\
\hline
\end{tabular}

${ }^{\mathrm{v}}$ Letters following data in columns, when different, indicates significant differences according to Fisher's protected least significant difference test $(P<0.05)$.

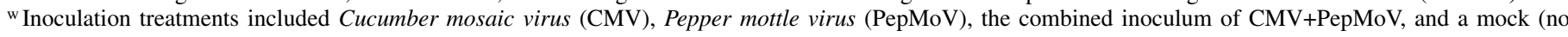
virus) control.

x Symptom ratings for each phase are presented in Table 1 . The sum represents the symptom severity rating value for phase $1+$ phase $2+$ phase 3 (equation $2 a$ ).

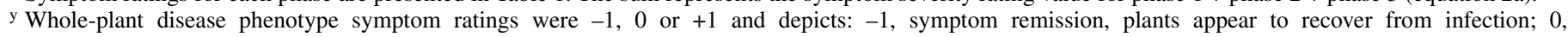
symptomatology similar to that during preceding phases; and +1 , symptoms more severe than during preceding phases with continued plant decline.

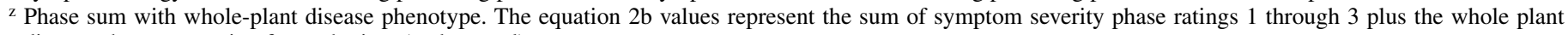
disease phenotype rating for each virus (and control) treatment. 
phase 2 remained as originally observed. Overall, CMV-infected plants were less severely affected in phase 3 than in the previous two phases. CMV symptom ratings averaged 1.1 for phase 3 . Symptom severity through phase 3 for PepMoV-infected plants remained similar to that observed for phases 1 and 2, with continued development of mottled, smaller-than-normal leaves (Fig. $1, \mathrm{P})$. PepMoV symptom ratings averaged 2.1 for phase 3 . Phase 3 for CMV+PepMoV-infected plants was a continuation in plant decline, with no extension of the stem above the point at which the stem branched; all newly emerged leaves were very small and bunched together at the top of the stem (Fig. 1, C+P). Necrosis became apparent for tissues associated with the apical bud and some newly emerged leaves. CMV+PepMoV symptom ratings averaged 3.0 for phase 3 .

A key distinguishing factor for $\mathrm{CMV}+\mathrm{PepMoV}$ disease severity relative to either virus alone occurred at or shortly after stem branching and through phase 3 . Upon reaching the stem-branching stage of growth, plants infected with either CMV or PepMoV continued to grow and develop and, in the case of CMV infection, plants recovered with little or no pronounced foliar symptoms. In contrast, $\mathrm{CMV}+\mathrm{PepMoV}$-infected plants continued to decline, with some apical necrosis leading to a halt in growth and development. A final symptom rating was incorporated, referred to as whole-plant disease phenotype, that was based less on specific types of symptoms and more on overall symptom appearance, plant growth, and development during the course of the experiment. The symptom severity rating for each virus treatment in each symptom phase was incorporated into equation $2 \mathrm{a}$ along with a whole-plant disease phenotype included in equation $2 b$ to test for synergy (Table 3 ). CMV-infected plants continued to grow and develop, with a remission in overall symptom severity leading to an average whole-plant disease phenotype rating of -0.9 (Table 3). In contrast, PepMoV symptoms were similar through each phase, resulting in an overall average whole-plant disease phenotype rating of -0.2 . The more severe symptoms in $\mathrm{CMV}+$ PepMoV-infected plants resulted in higher severity ratings for phases 1,2 , and 3 , with a continued increase in disease severity for a whole-plant disease phenotype rating of +1 .

Because symptom ratings are qualitative, equation 1 cannot be applied to these data for testing the possibility of a synergistic response (proportionalities cannot be assigned to ratings). However, the rating of plants co-infected with both viruses is neither less than nor equal to the ratings given to both plants infected with either virus alone, and this indicates the possibility of synergy rather than antagonism. When disease ratings were subjected to factorial analysis, the interaction term for the sum of the phases (equation $2 \mathrm{a}$ ) and the sum of the phases with whole-plant disease phenotype (equation 2 b) were highly significant (Table 3 ), demonstrating synergy using symptom severity ratings. The level of significance proving synergy increased when the whole-plant disease phenotype was factored into the equation (equation $2 b$ ).
The synergy identified for the $\mathrm{CMV}+\mathrm{PepMoV}$ treatment was visually apparent (Fig. 1) and demonstrated in Table 3.

Synergism based on virus accumulation. In trial 2, significantly less CMV accumulated in leaves of co-infected plants at 10 dpi compared with plants infected with CMV alone; however, by $21 \mathrm{dpi}$, significantly more CMV was detected in co-infected than singly infected plants (Table 4). In trial 3, no difference in CMV accumulation occurred between singly and co-infected plants at $10 \mathrm{dpi}$; however, significantly more CMV was detected in co-infected than singly infected plants at $21 \mathrm{dpi}$. The interaction was not significant at 10 dpi in either trial but was highly significant at $21 \mathrm{dpi}$ for both trials.

PepMoV accumulation in noninoculated leaves of singly versus doubly infected pepper plants did not differ at 10 or $21 \mathrm{dpi}$ in trials 2 and 3 (Table 4). No significant interaction occurred for PepMoV at either time point or trial in plants that were inoculated with PepMoV alone or in combination with CMV.

\section{DISCUSSION}

We showed that Abbott's equation for synergy can be used with plant virus-host interactions. A synergistic interaction between $\mathrm{CMV}+\mathrm{PepMoV}$ was manifested through host growth parameters relative to effects of each virus alone. Various growth parameters have been used with other virus-host systems to determine synergy although, in some cases, synergism was identified when values associated with the mixed infection were greater than the combined value from the single infections without further proof. However, as noted by Kosman and Cohen (18) with fungicide mixtures, "...clear, generally accepted definitions of synergism... [are] still absent." We used the Abbott approach (equation 1 herein) with statistical proof of dependence as a means to demonstrate a synergistic interaction of $\mathrm{CMV}+\mathrm{PepMoV}$ as measured by effects on plant height and weight relative to each virus alone.

Of particular interest to this project, however, was the ability to demonstrate synergy based on symptom severity. If each viral treatment results in a characteristic systemic symptom and the mixed infection is not lethal but extremely severe, proof of synergy based on symptom severity can be difficult. The CMV+PepMoV infection resulted in extremely severe symptoms, but this occurred well after both viruses already had spread systemically from the original source leaves of infection. Leaves that emerged prior to branching contained both viruses (shown using ELISA) but were only slightly more severely affected than comparable leaves in plants infected with each virus alone. These leaves were expanding at the time of infection and were likely in a sink-source developmental transition; their infection after emergence may have included both viruses, with the corresponding severe effects due to the CMV+PepMoV synergistic interaction. In contrast, leaves at and beyond the branching point of the stem likely became infected with both viruses early in their development, result-

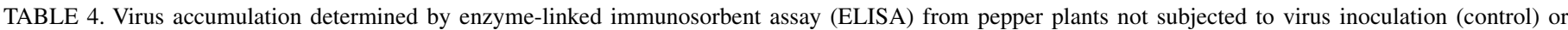
inoculated with Cucumber mosaic virus (CMV), Pepper mottle virus (PepMoV), or a combined inoculum of CMV+PepMoV ${ }^{\mathrm{z}}$

\begin{tabular}{|c|c|c|c|c|c|c|c|c|}
\hline \multirow[b]{3}{*}{ Treatment } & \multicolumn{4}{|c|}{ Trial 2} & \multicolumn{4}{|c|}{ Trial 3} \\
\hline & \multicolumn{2}{|c|}{$10 \mathrm{dpi}$} & \multicolumn{2}{|c|}{$21 \mathrm{dpi}$} & \multicolumn{2}{|c|}{$10 \mathrm{dpi}$} & \multicolumn{2}{|c|}{$21 \mathrm{dpi}$} \\
\hline & CMV & PepMoV & CMV & PepMoV & CMV & PepMoV & CMV & PepMoV \\
\hline None (control) & $0.09 \mathrm{c}$ & $0.095 \mathrm{~b}$ & $0.088 \mathrm{~b}$ & $0.09 \mathrm{~b}$ & $0.16 \mathrm{~b}$ & $0.21 \mathrm{~b}$ & $0.11 \mathrm{c}$ & $0.15 \mathrm{~b}$ \\
\hline Inoculated with PepMoV & $0.09 \mathrm{c}$ & $0.79 \mathrm{a}$ & $0.088 \mathrm{~b}$ & $1.26 \mathrm{a}$ & $0.16 \mathrm{~b}$ & $1.18 \mathrm{a}$ & $0.11 \mathrm{c}$ & $0.97 \mathrm{a}$ \\
\hline Inoculated with CMV & $0.90 \mathrm{a}$ & $0.095 \mathrm{~b}$ & $0.213 \mathrm{~b}$ & $0.09 \mathrm{~b}$ & $0.97 \mathrm{a}$ & $0.21 \mathrm{~b}$ & $0.39 \mathrm{~b}$ & $0.17 \mathrm{~b}$ \\
\hline Inoculated with CMV+PepMoV & $0.55 \mathrm{~b}$ & $0.69 \mathrm{a}$ & $1.03 \mathrm{a}$ & $1.14 \mathrm{a}$ & $1.03 \mathrm{a}$ & $1.23 \mathrm{a}$ & $1.02 \mathrm{a}$ & $1.08 \mathrm{a}$ \\
\hline$P$ of CMV as main effect & $<0.0001$ & 0.213 & $<0.0001$ & 0.45 & $<0.0001$ & 0.667 & $<0.0001$ & 0.912 \\
\hline$P$ of PepMoV as main effect & 0.008 & $<0.0001$ & $<0.0001$ & $<0.0001$ & 0.402 & $<0.0001$ & $<0.0001$ & $<0.0001$ \\
\hline$P$ of interaction & $0.13 \mathrm{~ns}$ & $0.218 \mathrm{~ns}$ & $<0.0001$ & $0.385 \mathrm{~ns}$ & $0.872 \mathrm{~ns}$ & $0.582 \mathrm{~ns}$ & $<0.0001$ & $0.312 \mathrm{~ns}$ \\
\hline
\end{tabular}

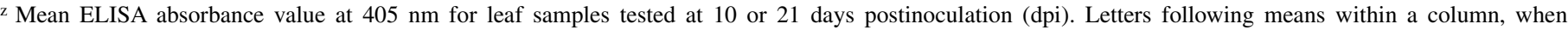
different, indicate a significant difference according to Fisher's protected means separation $(P<0.05)$; ns $=$ not significant. Data were also analyzed as a two-bytwo factorial (two viruses, each either mock or actually inoculated), and $P$ reflects the significance of those factor effects. 
ing in severe alterations in subsequent growth and development. Synergy of the mixed infection clearly occurred after the plant achieved a developmental stage of branching which likely coincided with CMV+PepMoV infection of newly emerging tissues.

CMV accumulation in noninoculated leaves of singly infected plants declined from 10 to $21 \mathrm{dpi}$ in each experiment, which coincided with the decrease in symptom severity ratings in phases 2 and (especially) 3. This decline in CMV accumulation did not occur, however, in CMV+PepMoV-infected plants. At 21 dpi, significantly more CMV was detected in noninoculated leaves of $\mathrm{CMV}+\mathrm{PepMoV}$-infected plants than in plants infected by CMV alone. In contrast, PepMoV accumulation did not differ in singly or co-infected plants. These findings suggest that the dramatic increase in symptom severity in co-infected plants may result, in part, from the continued levels of CMV accumulation in young, developing tissues rather than the decline in virus accumulation and coincidental decline in symptom severity in CMV-infected plants.

It is common to observe an increase in accumulation of one or both viruses in co-infected plants relative to plants infected with either virus alone $(3,6,7,17,25,28-30,33-35)$. In at least two reports, one of the viral components of a mixed infection decreased in accumulation relative to single infections $(10,25)$. Alleviation in restricted movement of one virus when co-infected with a second virus resulted in increased disease severity and, of course, an increase in the formerly restricted virus's accumulation in the newly invaded leaves $(7,17,28,34)$. For CMV and PepMoV in pepper, accumulation of the Potyvirus (PepMoV) was not altered in co-infected plants; however, there was a significant increase for CMV in co-infected plants during the later stages of the experiment. The decrease in CMV accumulation that occurs in symptom phases 2 and 3 leaves in singly infected plants may be due to virus-induced gene silencing $(9,11)$, although CMV and viruses in the genus Potyvirus are capable of suppressing the host plant's ability to silence viral RNA $(1,5)$. CMV may not be able to suppress the silencing mechanism in pepper plants; however, this may be circumvented by co-infection with PepMoV as shown for Potato virus $X$ and Potato virus $Y$ in tobacco $(26,33)$. It is unclear from our current data whether CMV accumulation is enhanced by the presence of PepMoV, the host's ability to recover is inhibited, or some combination thereof; however, it is clear that symptom severity increased dramatically due to the presence of both viruses in developing and emerging tissues.

The results presented in this report were extremely consistent, with each symptom phase occurring at a predictable stage of plant growth. Because plants were inoculated at the early seven- to eight-leaf stage, it is possible that extreme symptom development would have occurred more rapidly if plants were inoculated at an earlier stage of development. We did not determine whether the synergistic response resulted from the timely arrival of both viruses into newly emerging tissues or whether the occurrence of both viruses in newly developing tissues simply led to dramatic changes in cellular physiology and subsequent tissue development. The predictability of this system, however, will allow us to address such issues for future research.

\section{ACKNOWLEDGMENTS}

We thank S. Gray for review of the manuscript.

\section{LITERATURE CITED}

1. Anandalakshmi, R., Pruss, G. J., Ge, X., Marathe, R., Mallory, A. C., Smith, T. H., and Vance, V. B. 1998. A viral suppressor of gene silencing in plants. Proc. Natl. Acad. Sci. USA 95:13079-13084.

2. Andrianifahanana, M., Lovins, K., Dute, R., Sikora, E. J., and Murphy, J. F. 1997. Pathway for phloem-dependent movement of pepper mottle potyvirus in the stem of Capsicum annuиm. Phytopathology 87: 892-898.
3. Anjos, J. R., Jarlfors, U., and Ghabrial, S. A. 1992. Soybean mosaic potyvirus enhances the titer of two comoviruses in dually infected soybean plants. Phytopathology 82:1022-1027.

4. Bowen, K. L., Murphy, J. F., Flanders, K. L. and Li, R. 2003. Incidence of viruses infecting winter wheat in Alabama. Plant Dis. 87:288-293.

5. Brigneti, G., Voinnet, O., Li, W.-X., Ji, L.-H., Ding, S.-H., and Baulcombe, D. C. 1998. Viral pathogenicity determinants are suppressors of transgene silencing in Nicotiana benthamiana. EMBO J. 17:67396746.

6. Calvert, L. A., and Ghabrial, S. A. 1983. Enhancement by soybean mosaic virus of bean pod mottle virus titer in doubly infected soybean. Phytopathology 73:992-997.

7. Choi, S. K., Yoon, J. Y., Ryu, K. H., Choi, J. K., Palukaitis, P., and Park, W. M. 2002. Systemic movement of a movement-deficient strain of $\mathrm{Cu}$ cumber mosaic virus in zucchini squash is facilitated by a cucurbitinfecting potyvirus. J. Gen. Virol. 83:3173-3178.

8. Damirdagh, I. S., and Ross, A. F. 1967. A masked synergistic interaction of potato virus $\mathrm{X}$ and $\mathrm{Y}$ in inoculated leaves of tobacco. Virology 31:296307.

9. Dougherty, W. G., and Parks, T. D. 1995. Transgenes and gene suppression: Telling us something new? Curr. Opin. Cell Biol. 7:399-405.

10. Dufresne, D. J., Valverde, R. A., and Hobbs, H. A. 1999. Effect of coinfections of Andean potato mottle comovirus with two potyviruses in seven Capsicum genotypes. Rev. Mex. Fitopatol. 17:17-22.

11. English, J. J., Mueller, E., and Baulcombe, D. C. 1996. Suppression of virus accumulation in transgenic plants exhibiting silencing of nuclear genes. Plant Cell 8:787-797.

12. Fukumoto, F., Masuda, Y., and Hanada, K. 2003. Pea tissue necrosis induced by Cucumber mosaic virus alone or together with Watermelon mosaic virus. Plant Dis. 87:324-328.

13. Garcia-Ruiz, H., and Murphy, J. F. 2001. Age-related resistance in bell pepper to Cucumber mosaic virus. Ann. Appl. Biol. 139:307-317.

14. Gisi, U. 1996. Synergistic interaction of fungicides in mixtures. Phytopathology 86:1273-1279.

15. Guerini, M. N., and Murphy, J. F. 1999. Resistance of Capsicum annuиm 'Avelar' to pepper mottle potyvirus and alleviation of this resistance by co-infection with cucumber mosaic cucumovirus are associated with virus movement. J. Gen. Virol. 80:2785-2793.

16. Hu, W. W., Wong, S. M., Loh, C. S., and Goh, C. J. 1998. Synergism in replication of Cymbidium mosaic potexvirus (CymMV) and Odontoglossum ringspot tobamovirus (ORSV) RNA in orchid protoplasts. Arch. Virol. 143:1265-1275.

17. Karyeija, R. F., Kreuze, J. F., Gibson, R. W., and Valkonen, J. P. T. 2000. Synergistic interactions of a potyvirus and a phloem-limited crinivirus in sweet potato plants. Virology 269:26-36.

18. Kosman, E., and Cohen, Y. 1996. Procedures for calculating and differentiating synergism and antagonism in action of fungicide mixtures. Phytopathology 86:1263-1272.

19. Kuhn, C. W., and Dawson, W. O. 1973. Multiplication and pathogenesis of cowpea chlorotic mottle virus and southern bean mosaic virus in single and double infections in cowpea. Phytopathology 63:1380-1385.

20. Murphy, J. F. 2002. The relationship between virus source leaf and spread of infection through the stem of Capsicum sp. Arch. Virol. 147:17891797.

21. Murphy, J. F., Li, R., Kemble, J. M., Baltikauski, M., Porch, D., Gray, G., and Beauchamp, R. R. 2000. Viruses identified in commercial pumpkin and watermelon. Highlights Agric. Res. Auburn Univ. 47:7-9.

22. Murphy, J. F., Sikora, E. J., Slack, S., and Guerini, M. N. 2000. Six viruses identified in Irish potato plants grown in Alabama, U.S.A. Can. J. Plant Pathol. 22:315-318.

23. Niblett, C. L., and Claflin, L. E. 1978. Corn lethal necrosis- a new virus disease of corn in Kansas. Plant Dis. Rep. 62:15-19.

24. Pio-Ribeiro, G., Wyatt, S. D., and Kuhn, C. W. 1978. Cowpea stunt: A disease caused by a synergistic interaction of two viruses. Phytopathology 68:1260-1265

25. Poolpol, P., and Inouye, T. 1986. Enhancement of cucumber mosaic virus multiplication by zucchini yellow mosaic virus in doubly infected cucumber plants. Ann. Phytopathol. Soc. Jpn. 52:22-30.

26. Pruss, G., Ge, X., Shi, X. M., Carrington, J. C., and Vance, V. B. 1997. Plant viral synergism: The potyviral genome encodes a broad-range pathogenicity enhancer that transactivates replication of heterologous viruses. Plant Cell 9:859-868.

27. Ross, J. P. 1968. Effect of single and double infections of soybean mosaic and bean pod mottle viruses on soybean yield and seed characters. Plant Dis. Rep. 52:344-348.

28. Sano, Y., and Kojima, M. 1989. Increase in cucumber mosaic virus concentration in Japanese radish plants co-infected with turnip mosaic virus. Ann. Phytopathol. Soc. Jpn. 55:296-302.

29. Scholthof, K. G. 1999. A synergism induced by satellite panicum mosaic virus. Mol. Plant-Microbe Interact. 12:163-166. 
30. Sheets, K. 1998. Maize chlorotic mottle machlomovirus and wheat streak mosaic rymovirus concentrations increase in the synergistic disease corn lethal necrosis. Virology 242:28-38.

31. Sikora, E. J., Gudauskas, R. T., Murphy, J. F., Porch, D. W., Andrianifahanana, M., Zehnder, G. W., Bauske, E. M., Kemble, J. M., and Lester, D. 1998. A multivirus epidemic of tomatoes in Alabama. Plant Dis. 82:117-120.

32. Steel, R. G. D., and Torrie, J. H. 1980. Principles and Procedures of Statistics: A Biometrical Approach, 2nd ed. McGraw-Hill Book Co.,
New York.

33. Vance, V. B. 1991. Replication of potato virus $\mathrm{X}$ is altered in coinfections with potato virus Y. Virology 182:486-494.

34. Wang, Y., Gaba, V., Yang, J., Palukaitis, P., and Gal-On, A. 2002. Characterization of synergy between Cucumber mosaic virus and potyviruses in cucurbit hosts. Phytopathology 92:51-58.

35. Wintermantel, W. M. 2005. Co-infection of Beet mosaic virus with beet yellowing viruses leads to increased symptom expression on sugar beet. Plant Dis. 89:325-331. 